\title{
Anthony John Hall - Consultant Orthopaedic Surgeon
}

Published online: 25 March 2020

(C) SICOT aisbl 2020

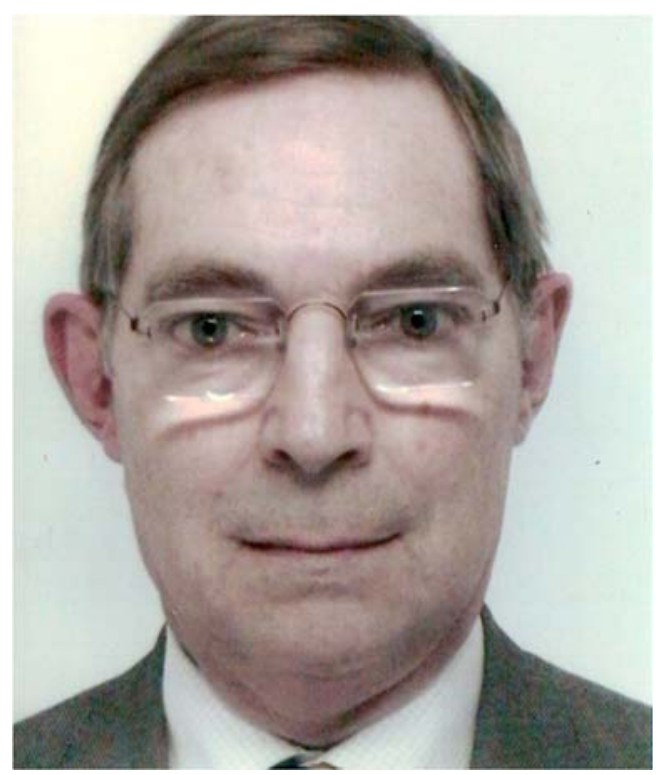

Tony Hall sadly passed away in February of this year after a battle with cancer. Tony leaves behind his wife, Avis and their three children Simon, Charles and Julia. He also leaves his grandchildren Abygail, Jake and Mya, Samuel, Josephine and Matilda.

SICOT and International Orthopaedics have lost a great champion and tireless supporter.

Tony trained at University College Hospital, London, qualifying in 1962. He completed his orthopaedic training via the Royal National Orthopaedic Hospital before taking up a consultant post at Charing Cross Hospital in 1973. He remained at Charing Cross taking the post of Post Graduate sub-dean in 1978. He was a consultant at Chelsea and Westminster Hospital from 1990 to 2001. During his working life he was a Member of the Court of Examiners of the Royal College of Surgeons and Member of Council of the British Orthopaedic Association. He was Chairman of the organising committee of the BOA Meeting at Wembley in 1992. In regard to SICOT he was a member of the organising committee of the SICOT Congress London 1984, he was National Delegate between
1990 and 1993 and General Secretary between 1993 and 2002. Finally, he was the chief examiner for SICOT from 2002 until recently. In regard to International Orthopaedics he was Deputy Editor from 1987 until 2013 serving on the Editorial Board during that time.

It is often said that we stand on the shoulders of giants. The best-known use of this phrase was by Isaac Newton in a letter to his rival Robert Hooke, in 1676: "What Descartes did was a good step. You have added much several ways, and especially in taking the colours of thin plates into philosophical consideration. If I have seen a little further it is by standing on the shoulders of Giants." Tony is that Giant to us that remain. He was a true son of Yorkshire in that he was uncomplicated, straight talking, true and honest. These are wonderful attributes which made him a great mentor, colleague, companion and friend. With Tony you knew he always 'had your back'. Winston Churchill is quoted as saying "we make a living by what we get, but we make a life by what we give". This again describes Tony. He gave so much of himself to other people and other causes. He was a great supporter of charitable organisations being always selfless, generous and kind. He looked for the best in people. Mr. Churchill also said "courage is what it takes to stand up and speak; courage is also what it takes to sit down and listen". These are attributes of great men in whose number Tony can be counted. He was not afraid of expressing views which may be controversial, but which made an important contribution. He was always honest and selfless, working for the common good. At the same time, he respected the views of others.

Tony had the respect and love of SICOT and the Board of International Orthopaedics for whom he did so much valued work. He was responsible for many people joining SICOT including me. His work with the SICOT examination in Orthopaedics was exemplary, setting attainable standards and going about his business with fairness to all. It says something about the man that there have been so many emails from his colleagues expressing warm feeling for him and expressing great sadness at his loss.

Tony had a warm wit and was always great company. He had an ability to make all around him feel included and 
valued. He wanted to know about you as an individual making you feel special and important. He was charming and generous host, with Avis making a great social 'team' from which many benefitted.

Tony knew he was ill and was aware of the outcome. That did not stop him continuing to engage with all around him and continuing to provide his experience and advice to all that requested it from him. He continued to engage with SICOT and International Orthopaedics where we all appreciated his sense of fairness and 'what was right'.

He will be enormously be missed by not only me but his family, colleagues and friends. There will be a Thanksgiving Service once the current medical emergency passes.

Andrew Quaile

Deputy Editor International Orthopaedics 